\title{
Comparing clinical outcomes of repeat discectomy versus fusion for recurrent disc herniation utilizing the $\mathbf{N}^{2} \mathbf{Q O D}$
}

\author{
Jian Guan, MD, Vijay M. Ravindra, MD, MSPH, Meic H. Schmidt, MD, MBA, Andrew T. Dailey, MD, \\ Robert S. Hood, MD, and Erica F. Bisson, MD, MPH
}

Department of Neurosurgery, Clinical Neurosciences Center, University of Utah, Salt Lake City, Utah

\begin{abstract}
OBJECTIVE Recurrent lumbar disc herniation (RLDH) is a significant cause of morbidity in patients undergoing lumbar discectomy and has been reported to occur in up to $18 \%$ of cases. While repeat discectomy is often successful in treating these patients, concern over repeat RLDH may lead surgeons to advocate instrumented fusion even in the absence of instability. The authors' goal was to compare clinical outcomes for patients undergoing repeat discectomy versus instrumented fusion for RLDH.
\end{abstract}

METHODS The authors used the National Neurosurgery Quality and Outcomes Database (N2QD) to assess outcomes of patients who underwent repeat discectomy versus instrumented fusion at a single institution from 2012 to 2015. Primary outcomes included Oswestry Disability Index (ODI) score, visual analog scale (VAS) score, and quality-adjusted life year (QALY) measures. Secondary outcomes included hospital length of stay, discharge status, and hospital charges.

RESULTS The authors identified 25 repeat discectomy and 12 instrumented fusion patients with 3-and 12-month follow-up records. The groups had similar ODI and VAS scores and QALY measurements at 3 and 12 months. Patients in the instrumented fusion group had significantly longer hospitalizations (3.7 days vs 1.0 days, $p<0.001)$ and operative times $(229.6$ minutes vs 82.7 minutes, $p<0.001)$. They were also more likely to be female $(p=0.020)$ and to be discharged to inpatient rehabilitation instead of home $(p=0.036)$. Hospital charges for the instrumented fusion group were also significantly higher $(\$ 54,458.29$ vs $\$ 11,567.05, p<0.001)$. Rates of reoperation were higher in the repeat discectomy group ( $12 \%$ vs $0 \%)$, but the difference was not statistically significant $(p=0.211)$.

CONCLUSIONS Repeat discectomy and instrumented fusion result in similar clinical outcomes at short-term follow-up. Patients undergoing repeat discectomy had significantly shorter operative times and length of stay, and they incurred dramatically lower hospital charges. They were also less likely to require acute rehabilitation postoperatively. Further research is needed to compare these two management strategies.

http://thejns.org/doi/abs/10.3171/2016.5.SPINE1616

KEY WORDS recurrent lumbar disc herniation; patient-reported outcomes; hospital charges; lumbar fusion; repeat lumbar discectomy

$\mathrm{R}$ ECURRENT lumbar disc herniation (RLDH) is a significant cause of morbidity in patients undergoing lumbar discectomy as it may occur in 5\%-18\% of patients..$^{3,5,11} \mathrm{RLDH}$ is thought to represent surgical failure, $, 2,8,10$ and multiple studies have examined which demographic and operative factors might contribute to its occurrence. ${ }^{12,14,16}$ Whether repeat discectomy or posterior instrumented fusion offers the best management for patients with recurrent disc herniation is a controversial topic. Repeat discectomy is often successful in treating these patients, but concern over repeat RLDH may lead many surgeons to advocate instrumented fusion in the absence of instability. To our knowledge, there are no direct comparisons of clinical outcomes and hospital charges for these patients in the literature.

We sought to compare the clinical and patient-reported outcomes for patients undergoing repeat discectomy versus instrumented fusion for RLDH by using the National

ABBREVIATIONS ASA = American Society of Anesthesiologists; $E Q=$ EuroQol; $N^{2} Q O D=$ National Neurosurgery Quality and Outcomes Database; $O D I=0$ swestry Disability Index; PEEK = polyetheretherketone; QALY = quality-adjusted life year; RLDH = recurrent lumbar disc herniation; VAS = visual analog scale.

SUBMITTED January 5, 2016. ACCEPTED May 26, 2016.

INCLUDE WHEN CITING Published online August 12, 2016; DOI: 10.3171/2016.5.SPINE1616. 
Neurosurgery Quality and Outcomes Database ( $\left.{ }^{2} \mathrm{QOD}\right)$. $\mathrm{N}^{2} \mathrm{QOD}$ is a national clinical registry that enables the prospective collection of data for a variety of neurosurgical conditions to facilitate studies promoting improvements in quality and outcomes. ${ }^{13}$ We hypothesized that patient-reported outcomes are similar between the two procedures but that length of surgery, length of hospital stay, and disposition status vary between the two.

\section{Methods \\ Study Population}

After obtaining approval from the institutional review board, we queried the $\mathrm{N}^{2} \mathrm{QOD}$ to obtain information about patients who underwent repeat discectomy or instrumented fusion for a diagnosis of recurrent herniated nucleus pulposus (ipsilateral or contralateral) at a single institution between November 2012 and May 2015. Eligible patients were 18 years or older and had at least 12 months of follow-up postoperatively.

\section{Preoperative Evaluation}

The decision about which treatment modality to use was based on a variety of clinical and radiographic variables and depended on the discretion of the operating surgeon. Preoperative MRI with and without contrast was performed prior to surgery in all cases to confirm that recurrent disc herniation and not scar tissue or other abnormality was the cause of patient's symptoms.

\section{Postoperative Care}

All patients were encouraged to begin ambulating on postoperative Day 1. All patients were seen and evaluated by the physical and occupational therapy team. Pain management was based on patient and treating physician preference. Discharge decisions were made in collaboration with the patient, the surgical team, the therapy team, and, when needed, the rehabilitation service. Prior to discharge home, all patients had to pass a physical therapy-administered home safety evaluation, demonstrate the ability to tolerate adequate oral intake, and have their pain well controlled utilizing oral pain medications alone.

\section{Data Collection}

We collected demographic and relevant medical history data, including sex, age, ethnicity (dichotomized into Caucasian and other), body mass index, tobacco use, American Society of Anesthesiologists (ASA) Physical Status Classification System (ASA class), education level, employment status, and presence of diabetes and/or hypertension. Preoperative data included predominant symptom (pain, weakness, or numbness), workers' compensation claim status, instability (as defined by motion on flexion/extension radiographs), Modic changes on preoperative MRI, preoperative listhesis, recurrence number (dichotomized into the first recurrence or later recurrences), time in years between the initial discectomy and the repeat surgery, and symptom duration. Primary outcomes included back and leg pain visual analog scale (VAS) scores, EuroQol (EQ)VAS score, quality-adjusted life year (QALY), and Oswes- try Disability Index (ODI) score at the 3-month follow-up. Secondary operative and perioperative outcomes data included length of surgery, length of stay, discharge destination, complication rates, and hospital charges. Secondary postoperative outcomes data included the ability to return to work within a year postoperatively, reoperation rates at follow-up and 12-month assessments of leg pain VAS score, back pain VAS score, EQ-VAS score, QALY, and ODI. Finally, for the instrumented fusion group, we evaluated fusion rates at the 12-month follow-up, defined as lack of motion on flexion/extension radiographs and/or bony bridging.

\section{Statistical Analysis}

Patients were separated into 2 groups based on whether they had repeat discectomy or posterior instrumented fusion for all analyses. Continuous variables were compared using the Student t-test, and categorical variables were compared using chi-square analysis. Significance was defined in all cases as $\mathrm{p}<0.05$. All calculations were performed using SPSS (IBM Corp.).

\section{Results}

We identified 25 patients who underwent repeat discectomy and 12 patients who underwent lumbar fusion for treatment of RLDH between November 2012 and May 2015 and satisfied inclusion criteria for analysis. Within the fusion group, patients underwent various types of surgery based on surgeon preference and surgical variables: 7 patients underwent a transforaminal lumbar interbody fusion, 3 had a minimally invasive transforaminal lumbar interbody fusion, and 2 underwent a posterior lumbar interbody fusion. A combination of autograft, allograft, and polyetheretherketone (PEEK) was used in 3 patients, PEEK and autograft were used in 2, autograft and allograft were used in 4, and PEEK, autograft, or allograft alone in 1 patient each. Patients treated with repeat discectomy and lumbar fusion had similar demographic characteristics including age, employment status, education level, body mass index, tobacco use, rates of diabetes, rates of hypertension, and race/ethnicity. Patients in the instrumented fusion group were significantly more likely to be female ( $58 \%$ vs $20 \%, \mathrm{p}=0.020$; Table 1 ). The ASA classes for the groups were not significantly different, with the majority of patients falling into ASA Class II (mild systemic disease). The predominant presenting symptom in both groups was numbness or pain, and the majority of patients had symptoms lasting 3 months or longer. Patients involved in workers' compensation claims made up a minority in both groups. The mean time between initial/ previous discectomy and repeat procedure was $6.0 \pm 6.7$ years for the repeat discectomy group and $3.4 \pm 3.9$ years for the fusion group, and this difference was not statistically significant $(\mathrm{p}=0.224)$. Preoperative patient-reported outcomes, including ODI, VAS (back and leg), and EQVAS scores and QALY, were similar between the groups. No patient demonstrated radiographic instability prior to surgery in either group. Modic changes were seen in 56\% of repeat discectomy patients and $25 \%$ of fusion patients, a difference that was not statistically significant $(\mathrm{p}=0.077)$. 
TABLE 1. Demographic and preoperative data for patients with RLDH who underwent repeat discectomy or instrumented lumbar fusion

\begin{tabular}{|c|c|c|c|}
\hline Variable & $\begin{array}{l}\text { Repeat } \\
\text { Discectomy } \\
(n=25)^{*}\end{array}$ & $\begin{array}{l}\text { Lumbar } \\
\text { Fusion } \\
(n=12)^{*}\end{array}$ & $\begin{array}{c}p \\
\text { Value }\end{array}$ \\
\hline No. of females & $5(20)$ & $7(58)$ & 0.020 \\
\hline Mean age in yrs & $51.0 \pm 12.0$ & $53.4 \pm 15.2$ & 0.608 \\
\hline Mean BMI & $28.7 \pm 4.8$ & $28.7 \pm 5.0$ & 0.962 \\
\hline Tobacco use & $2(8)$ & $2(17)$ & 0.427 \\
\hline Diabetes & $4(16)$ & $2(17)$ & 0.959 \\
\hline Hypertension & $8(32)$ & $5(42)$ & 0.564 \\
\hline ASA class & & & 0.945 \\
\hline I & $4(16)$ & $2(17)$ & \\
\hline II & $18(72)$ & $9(75)$ & \\
\hline III & $3(12)$ & $1(8)$ & \\
\hline IV & $0(0)$ & $0(0)$ & \\
\hline Employment status & & & 0.123 \\
\hline Employed & $15(60)$ & $3(25)$ & \\
\hline Employed, not working & $3(12)$ & $1(8)$ & \\
\hline Unemployed & $7(28)$ & $7(58)$ & \\
\hline Predominant symptom & & & 0.243 \\
\hline Pain & $10(40)$ & $4(33)$ & \\
\hline Weakness & $4(16)$ & $0(0)$ & \\
\hline Numbness & $11(44)$ & $8(67)$ & \\
\hline য3-mo symptom duration & $18(72)$ & $11(92)$ & 0.174 \\
\hline Workers' compensation claim & $8(32)$ & $1(8)$ & 0.116 \\
\hline $\begin{array}{l}\text { Mean time btwn initial/previous } \\
\text { discectomy \& recurrent hernia- } \\
\text { tion in yrs }\end{array}$ & $6.0 \pm 6.7$ & $3.4 \pm 3.9$ & 0.224 \\
\hline Preop instability & $0(0)$ & $0(0)$ & - \\
\hline Preop MRI Modic changes & $14(56)$ & $3(25)$ & 0.077 \\
\hline Preop listhesis & $2(8)$ & $1(9)$ & 0.972 \\
\hline Education level & & & 0.134 \\
\hline$<$ High school & $1(4)$ & $0(0)$ & \\
\hline High school & $2(8)$ & $3(25)$ & \\
\hline 2-yr college & $13(52)$ & $4(33)$ & \\
\hline 4-yr college & $6(24)$ & $3(25)$ & \\
\hline Postcollege & $3(12)$ & $0(0)$ & \\
\hline NA & $0(0)$ & $2(17)$ & \\
\hline Race/ethnicity & & & 0.737 \\
\hline Caucasian & $22(88)$ & $11(92)$ & \\
\hline Other & $3(12)$ & $1(8)$ & \\
\hline $\begin{array}{l}\text { No. of recurrences of lumbar disc } \\
\text { herniation }\end{array}$ & & & 0.315 \\
\hline 1 & $22(88)$ & $9(75)$ & \\
\hline$\geq 2$ & $3(12)$ & $3(25)$ & \\
\hline Mean preop ODI score & $26.9 \pm 10.5$ & $24.8 \pm 9.7$ & 0.574 \\
\hline Mean preop back pain VAS score & $6.8 \pm 2.4$ & $7.7 \pm 2.1$ & 0.246 \\
\hline Mean preop leg pain VAS score & $7.2 \pm 2.2$ & $6.6 \pm 3.0$ & 0.442 \\
\hline Mean preop EQ-VAS score & $47.2 \pm 22.6$ & $37.7 \pm 21.7$ & 0.249 \\
\hline
\end{tabular}

CONTINUED IN NEXT COLUMN »
» CONTINUED FROM PREVIOUS COLUMN

TABLE 1. Demographic and preoperative data for patients with RLDH who underwent repeat discectomy or instrumented lumbar fusion

\begin{tabular}{lccc}
\hline \multicolumn{1}{c}{ Variable } & $\begin{array}{c}\text { Repeat } \\
\text { Discectomy } \\
(\mathrm{n}=25)^{*}\end{array}$ & $\begin{array}{c}\text { Lumbar } \\
\text { Fusion } \\
(\mathrm{n}=12)^{*}\end{array}$ & $\begin{array}{c}\mathrm{p} \\
\text { Value }\end{array}$ \\
\hline Mean preop QALY & $0.44 \pm 0.21$ & $0.42 \pm 0.15$ & 0.813 \\
\hline Mean follow-up duration in yrs & $2.2 \pm 0.75$ & $2.2 \pm 0.69$ & 0.914 \\
\hline
\end{tabular}

$\mathrm{BMI}=$ body mass index; $\mathrm{NA}=$ not available; $-=$ not applicable.

* Values are presented as the number of patients (\%) unless otherwise specified. Mean values are presented as the mean \pm SD.

$\dagger p<0.05$ was considered significant.

Rates of preoperative listhesis were also similar between the groups. Patients in the repeat discectomy group were more likely to be receiving treatment for their first RLDH than those in the fusion group (88\% vs $75 \%$ ), but this difference also was also not statistically significant ( $\mathrm{p}=$ $0.315)$.

The mean follow-up duration was $2.2 \pm 0.75$ years for the repeat discectomy group (range 1.0-3.4 years) and $2.2 \pm 0.69$ years for the instrumented fusion group (range 1.2-3.2 years). Three-month follow-up data for ODI were available for all 37 patients, and the remaining primary outcomes data were available for $95 \%$ or more of patients (Table 2). All patient-reported outcomes were similar in the 2 groups at both the 3- and 12-month follow-ups. For our primary outcomes, the mean ODI score at 3 months was $11.9 \pm 8.9$ in the repeat discectomy group and $13.1 \pm$ 9.3 in the fusion group. The mean 3-month back and leg pain VAS scores were $3.0 \pm 3.1$ and $2.6 \pm 2.3$, respectively, in the repeat discectomy group and $3.6 \pm 2.4$ and $2.8 \pm$ 2.6 , respectively, in the fusion group. The mean QALY at 3 months was $0.74 \pm 0.24$ in the repeat discectomy group and $0.70 \pm 0.19$ in the fusion group. None of these differences was statistically significant $(p \geq 0.05)$. There were no significant differences in rates of complications between the discectomy and the fusion groups, with dural tears being the only adverse event and occurring in 2 patients in each group $(\mathrm{p}=0.43)$.

For our secondary outcomes, 12-month patient-reported outcomes data were available in at least 33 of 37 cases (89\%) for all outcomes: 22 (88\%) in the repeat discectomy group and $11(92 \%)$ in the instrumented fusion group. There were no significant differences in any of our 4 patient-reported outcomes between the repeat discectomy and instrumented fusion groups at the 12-month follow-up. Patients in the repeat discectomy group had a significantly shorter length of stay than those in the instrumented fusion group $(1.0 \pm 0.3$ days vs $3.7 \pm 0.9$ days, $p<0.001)$ and had significantly shorter operative times $(82.7 \pm 29.1 \mathrm{~min}$ utes vs $229.6 \pm 42.1$ minutes, $p<0.001$ ) (Table 3). Patients in the repeat discectomy group were also significantly more likely to be able to discharge home $(100 \%$ vs $83 \%$, $\mathrm{p}=0.036$ ). Three patients in the repeat discectomy group $(12 \%)$ needed additional repeat surgery by the time of last follow-up because of repeat RLDH, while none in the instrumented fusion group needed reoperation; this differ- 
TABLE 2. Subjective outcomes for patients with RLDH who underwent repeat discectomy or instrumented lumbar fusion

\begin{tabular}{lccc}
\hline Outcome & $\begin{array}{c}\text { Repeat } \\
\text { Discectomy }\end{array}$ & $\begin{array}{c}\text { Lumbar Fusion } \\
\text { Value* }\end{array}$ \\
\hline Mean 3-mo ODI & $11.9 \pm 8.9(n=25)$ & $13.1 \pm 9.3(n=12)$ & 0.706 \\
\hline Mean 12-mo ODI & $11.6 \pm 8.2(n=23)$ & $15.6 \pm 9.5(n=11)$ & 0.222 \\
\hline $\begin{array}{c}\text { Mean 3-mo back } \\
\text { pain VAS }\end{array}$ & $3.0 \pm 3.1(n=24)$ & $3.6 \pm 2.4(n=12)$ & 0.598 \\
\hline $\begin{array}{c}\text { Mean 12-mo back } \\
\text { pain VAS }\end{array}$ & $3.3 \pm 2.9(n=23)$ & $4.2 \pm 3.2(n=11)$ & 0.430 \\
\hline $\begin{array}{l}\text { Mean 3-mo leg } \\
\text { pain VAS }\end{array}$ & $2.6 \pm 2.3(n=24)$ & $2.8 \pm 2.6(n=12)$ & 0.808 \\
\hline $\begin{array}{l}\text { Mean 12-mo leg } \\
\text { pain VAS }\end{array}$ & $3.2 \pm 3.4(n=23)$ & $3.8 \pm 2.9(n=11)$ & 0.589 \\
\hline $\begin{array}{l}\text { Mean 3-mo EQ- } \\
\text { VAS }\end{array}$ & $66.7 \pm 19.7(n=23)$ & $66.0 \pm 22.9(n=12)$ & 0.921 \\
\hline $\begin{array}{l}\text { Mean 12-mo EQ- } \\
\text { VAS }\end{array}$ & $67.5 \pm 24.1(n=22)$ & $61.2 \pm 23.4(n=11)$ & 0.479 \\
\hline $\begin{array}{l}\text { Mean 3-mo QALY } \\
\text { Mean 12-mo }\end{array}$ & $0.74 \pm 0.24(n=24)$ & $0.70 \pm 0.19(n=12)$ & 0.634 \\
\hline $\begin{array}{l}\text { QALY } \\
\text { * p }<0.05 \text { was considered significant. }\end{array}$ & $0.77 \pm 0.22(n=23)$ & $0.66 \pm 0.27(n=11)$ & 0.241 \\
\hline
\end{tabular}

ence was not significant ( $p=0.211$ ). Hospital charges were significantly higher for the fusion group than the repeat discectomy group $(\$ 54,458.29 \pm \$ 6160.29$ vs $\$ 11,567.05$ $\pm \$ 2937.44, \mathrm{p}<0.001)$. Of the 12 patients who underwent instrumented fusion, 11 (92\%) showed radiographic evidence of fusion at the 12-month follow-up. Of the patients who were working or employed but not working at the time of surgery, $89 \%$ of patients in the repeat discectomy group were able to return to work within 12 months, while $75 \%$ of the fusion group did so. This difference was not statistically significant $(\mathrm{p}=0.464)$.

\section{Discussion}

Despite the relatively high prevalence of RLDH after lumbar discectomy, its management ${ }^{17}$ and even its defini- tion-whether to include both ipsilateral and contralateral reherniations ${ }^{7}$ and the specific window of time after which a disc herniation may be considered recurrent versus a simple failure of the original surgery ${ }^{1}$-are the subjects of debate. The controversies are propagated by a lack of high-quality evidence comparing repeat discectomy and instrumented fusion head to head. ${ }^{4}$

Our study contributes to the understanding of optimal management for RLDH by examining a multitude of patient-reported and clinical outcomes in addition to hospital charges for the 2 preferred forms of intervention. Data for our study were obtained through the $\mathrm{N}^{2} \mathrm{QOD}$ database.

Patient-reported outcomes at both the 3-and 12-month follow-ups were similar in the 2 treatment groups. These findings support those from existing literature suggesting that both surgical interventions for RLDH are efficacious. ${ }^{6}$ Operative time, length of stay, rates of discharge to acute rehabilitation, and hospital charges, however, were all significantly higher in the instrumented fusion group than in the repeat discectomy group. Patients undergoing fusion were also more likely to be female. The cause for this difference is not definitively identifiable based on our study, although differential satisfaction with lumbar spine procedures between men and women has been reported in the literature,$^{15}$ and it is possible that women were more likely to elect for a different procedure after an initial failed discectomy as a result.

Despite these findings, it remains difficult to define the optimal intervention for RLDH. Although length of stay was longer in the fusion cohort, the average hospitalization duration for this group was less than 4 days. Similarly, although discharge to acute rehabilitation was needed in a higher proportion of fusion patients than repeat discectomy patients, the vast majority of fusion patients - more than $80 \%$-were able to return home postoperatively.

Our study has several limitations. The first is its retrospective nature, although the utilization of the prospectively acquired $\mathrm{N}^{2} \mathrm{QOD}$ database likely ameliorates this to some degree. Our study data are drawn from a single center and our sample size is limited, thus limiting both the generalizability of our findings and raising the distinct possibility that our cohort is underpowered to find a sig-

TABLE 3. Objective outcomes for patients with RLDH who underwent repeat discectomy or instrumented lumbar fusion

\begin{tabular}{|c|c|c|c|}
\hline Outcome & Repeat Discectomy $(n=25)^{*}$ & Lumbar Fusion $(n=12)^{*}$ & $\mathrm{p}$ Value \\
\hline Mean LOS (days) & $1.0 \pm 0.3$ & $3.7 \pm 0.9$ & $<0.001$ \\
\hline Mean length of surgery (mins) & $82.7 \pm 29.1$ & $229.6 \pm 42.1$ & $<0.001$ \\
\hline Discharge location & & & 0.036 \\
\hline Home & $25(100)$ & $10(83)$ & \\
\hline Inpatient rehabilitation & $0(0)$ & $2(17)$ & \\
\hline Mean hospital charges & $\$ 11,567.05 \pm \$ 2937.44$ & $\$ 54,458.29 \pm \$ 6160.29$ & $<0.001$ \\
\hline Need for repeat surgery at follow-up & $3(12)$ & $0(0)$ & 0.211 \\
\hline Bony fusion at $12-$ mo follow-up & - & $11(92)$ & - \\
\hline Complications/adverse events & $2(8)$ & $2(17)$ & 0.427 \\
\hline Returned to work w/in 12 mos (repeat discectomy, $n=18$; lumbar fusion, $n=3$ ) & $16(89)$ & $3(75)$ & 0.464 \\
\hline
\end{tabular}

LOS = length of stay; $-=$ not applicable.

* Values are presented as the number of patients (\%) unless otherwise specified.

$\dagger p$ value $<0.05$ was considered significant. 
nificant difference in our patient-reported outcomes. Indeed, based on previous publications, ${ }^{4,6}$ thousands of cases would need to be analyzed to have an appropriately powered study comparing these treatments. The data for these studies themselves are generally gleaned from small, retrospective case series, however, and significant questions remain as to the magnitude of difference in outcome between repeat discectomy and fusion for RLDH.

Despite our limited power, we believe that our study highlights an important facet of the $\mathrm{N}^{2} \mathrm{QOD}$ initiative. The primary purpose of the $\mathrm{N}^{2} \mathrm{QOD}$ (http://www.neuropoint. org/NPA\%20N2QOD.aspx) is to "establish risk-adjusted national benchmarks for both the cost and quality of common neurosurgical procedures," and we believe that in the future such databases will allow for significant advancement of our knowledge on vital surgery-related outcomes. The second stated goal of the $\mathrm{N}^{2} \mathrm{QOD}$, however, is to "allow practice groups and hospitals to analyze their individual morbidity and clinical outcomes in real time." Although our data set is limited to our institution, our findings demonstrate significant differences in individual-level and hospital-level outcomes, specifically, the significantly longer operative time, length of stay, and need for rehabilitation among patients undergoing fusion compared with those undergoing repeat discectomy. These data will allow us to better counsel our patients, and we believe this study highlights the utility of the $\mathrm{N}^{2} \mathrm{QOD}$ as an agile, scalable resource rather than just a monolithic "big data" tool. Even though our findings are not necessarily surprising given the nature of the 2 surgical interventions, the magnitude of the differences between these procedures has previously not been investigated using a database such as the $\mathrm{N}^{2} \mathrm{QOD}$.

For our institution, until March 1, 2015, the first 6 patients who met inclusion criteria each week were enrolled in the lumbar $\mathrm{N}^{2} \mathrm{QOD}$ module. It is possible, therefore, that some patients with recurrent disc herniation were missed as a result, but if this is the case, we expect that any missed patients were done so at random and would not dramatically bias our results. Beginning March 1, 2015, all patients meeting the criteria for inclusion were enrolled. During the study period, 471 microdiscectomies were performed at our institution, for a recurrent disc herniation rate of $7.9 \%$. This is fairly consistent with previously published rates, and we believe it suggests that the majority of recurrent cases were captured in our cohort. ${ }^{3,5,11}$ Nevertheless, the possibility of missed cases is a significant limitation.

Twelve percent of the repeat discectomy patients in our group required reoperation in the follow-up period (Fig. 1), whereas none of the patients within the fusion group required another surgery. This difference was not statistically significant, however, and because of the relatively short follow-up period in our cohort and our small sample size, such a finding should be interpreted cautiously. At most, this suggests that a larger study involving multiple centers is needed to better define the true rate of reoperation within these 2 groups. Finally, the popularization of minimally invasive approaches to both primary and repeat discectomies $^{9}$ may change the surgical profile of repeat disc surgery, and investigations into the utilization and outcomes of these techniques are needed.

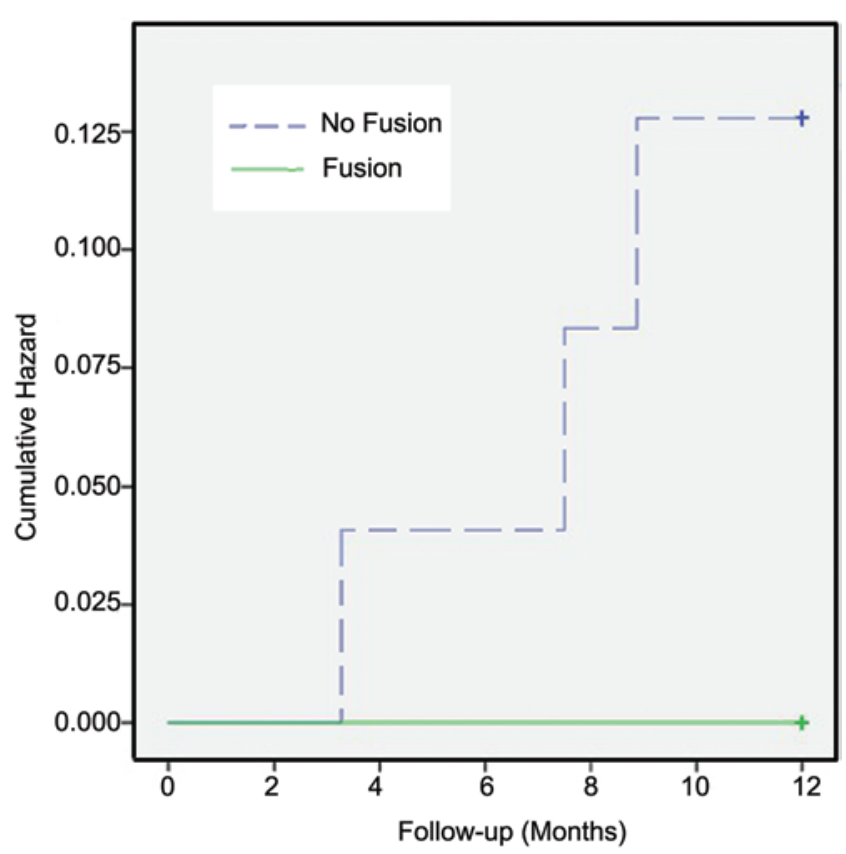

FIG. 1. Reoperation hazard plot. Figure is available in color online only.

\section{Conclusions}

For patients experiencing RLDH, repeat discectomy and instrumented fusion resulted in similar patient-reported outcomes on short-term follow-up. Repeat discectomy may offer multiple short-term benefits compared with instrumented fusion, but with such similarities in outcomes observed in our study, the choice of which surgery to offer must be individualized for each patient's specific needs and characteristics.

\section{References}

1. Aizawa T, Ozawa H, Kusakabe T, Nakamura T, Sekiguchi A, Takahashi A, et al: Reoperation for recurrent lumbar disc herniation: a study over a 20 -year period in a Japanese population. J Orthop Sci 17:107-113, 2012

2. Cinotti G, Roysam GS, Eisenstein SM, Postacchini F: Ipsilateral recurrent lumbar disc herniation. A prospective, controlled study. J Bone Joint Surg Br 80:825-832, 1998

3. Crock HV: Observations on the management of failed spinal operations. J Bone Joint Surg Br 58:193-199, 1976

4. Dower A, Chatterji R, Swart A, Winder MJ: Surgical management of recurrent lumbar disc herniation and the role of fusion. J Clin Neurosci 23:44-50, 2016

5. Ebeling U, Kalbarcyk H, Reulen HJ: Microsurgical reoperation following lumbar disc surgery. Timing, surgical findings, and outcome in 92 patients. J Neurosurg 70:397-404, 1989

6. Fu TS, Lai PL, Tsai TT, Niu CC, Chen LH, Chen WJ: Longterm results of disc excision for recurrent lumbar disc herniation with or without posterolateral fusion. Spine (Phila Pa 1976) 30:2830-2834, 2005

7. Greenleaf RM, Harris MB, Bono CM: The role of fusion for recurrent disk herniations. Semin Spine Surg 23:242-248, 2001

8. Guo JJ, Yang H, Tang T: Long-term outcomes of the revision open lumbar discectomy by fenestration: A follow-up study of more than 10 years. Int Orthop 33:1341-1345, 2009

9. Hubbe U, Franco-Jimenez P, Klingler JH, Vasilikos I, Scholz C, Kogias E: Minimally invasive tubular microdiscectomy 
for recurrent lumbar disc herniation. J Neurosurg Spine 24:48-53, 2016

10. Kim KT, Park SW, Kim YB: Disc height and segmental motion as risk factors for recurrent lumbar disc herniation. Spine (Phila Pa 1976) 34:2674-2678, 2009

11. Law JD, Lehman RA, Kirsch WM: Reoperation after lumbar intervertebral disc surgery. J Neurosurg 48:259-263, 1978

12. Leven D, Passias PG, Errico TJ, Lafage V, Bianco K, Lee A, et al: Risk factors for reoperation in patients treated surgically for intervertebral disc herniation: a subanalysis of eightyear SPORT data. J Bone Joint Surg Am 97:1316-1325, 2015

13. McGirt MJ, Speroff T, Dittus RS, Harrell FE Jr, Asher AL: The National Neurosurgery Quality and Outcomes Database $\left(\mathrm{N}^{2} \mathrm{QOD}\right)$ : general overview and pilot-year project description. Neurosurg Focus 34(1):E6, 2013

14. Moliterno JA, Knopman J, Parikh K, Cohan JN, Huang QD, Aaker GD, et al: Results and risk factors for recurrence following single-level tubular lumbar microdiscectomy. J Neurosurg Spine 12:680-686, 2010

15. Shabat S, Folman Y, Arinzon Z, Adunsky A, Catz A, Gepstein R: Gender differences as an influence on patients' satisfaction rates in spinal surgery of elderly patients. Eur Spine J 14:1027-1032, 2005

16. Shimia M, Babaei-Ghazani A, Sadat BE, Habibi B, Habibzadeh A: Risk factors of recurrent lumbar disk herniation.

Asian J Neurosurg 8:93-96, 2013
17. Stambough J: An algorithmic approach to recurrent lumbar disk herniation: evaluation and management. Semin Spine Surg 20:2-13, 2008

\section{Disclosures}

The authors report the following. Dr. Schmidt: consultant for Ulrich Medical USA. Dr. Dailey: consultant for Biomet and has received payment for lectures from AONA and grant funding from Biomet. Dr. Bisson: consultant for nView Medical.

\section{Author Contributions}

Conception and design: Bisson, Guan. Acquisition of data: Bisson, Guan, Ravindra. Analysis and interpretation of data: Guan. Drafting the article: Guan, Ravindra. Critically revising the article: Bisson, Guan, Schmidt, Dailey, Hood. Reviewed submitted version of manuscript: all authors. Approved the final version of the manuscript on behalf of all authors: Bisson.

\section{Correspondence}

Erica F. Bisson, Department of Neurosurgery, Clinical Neurosciences Center, University of Utah, 175 N Medical Dr. East, Salt Lake City, UT 84132. email: neuropub@hsc.utah.edu. 